\title{
Moral Agency in Pain Medicine: Philosophy, Practice and Virtue
}

\author{
James Giordano, $\mathrm{PhD}$
}

Although established as a field of specialization, pain medicine remains somewhat fractionated. Such lack of cohesion creates dissonance on multiple levels, and thus, impedes the provision of effective pain care. This paper asserts that there is a core philosophy of medicine that reflects the intellectual and moral quality of the healing relationship.

Although established as a field of specialization, pain medicine remains somewhat inchoate as influenced, respectively, by political and socio-economic forces within medicine and the medicolegal marketplace. This has both resulted from, and has further fostered multiple disciplines implicitly competing for authoritative hegemony of the field, and by extension, has affected the construct(s) and conduct of patient care. In the commodified environment that reflects much of contemporary medicine, such fractionation creates dissonance between clinicians, as well as in the physicianpatient relationship, detracts from the possibility of integrative practice, and impedes the provision of effective therapeutics.

In this paper I assert that there is a core philosophy of medicine that reflects the intellectual and moral quality of the

From: Center for Bioethics, Georgetown University Medical Center, Washington, DC, and John Mc-

Govern MD Center for Health, Humanities and the Human Spirit, University of Texas Health Sciences Center, Houston, TX

Address Corresspondence:

James Giordano, PhD

Scholar-in-Residence

Center for Clinical Bioethics

Georgetown University Medical Center

4000 Reservoir Rd.

Washington, DC 20057

E-mail: jgiordano@neurobioethics.org

Disclaimer: This work was supported, in part, by a

grant from the Hunt-Travis Foundation, and by the

Center for Clinical Bioethics, Georgetown Univer-

sity Medical Center.

Conflict of Interest: None

Manuscript received on 12/30/2005

Accepted for publication on 01/03/2005
I argue that pain medicine, in all its constituent disciplines, is bound to this philosophy. The intricate relationship between pain, the pain patient, and the pain physician creates pragmatic and moral dilemmas that may not be well served by the use of prima facie principles. It is argued that an agent-based, virtue ethics best enable the clinician to both

healing relationship, and which shapes and defines the ends (i.e., the telos) of medical practice. From this premise, I argue that pain medicine, in all of its constituent disciplines, is ineradicably bound to this philosophy. Consistent with this philosophy then, it is the particular nature of pain and its effect upon the existential predicament of the pain patient which dictates the essence of pain medicine as representative of the uniqueness of its practice. Through the act of profession, the clinician who holds forth to treat those in pain must be wholly dedicated to the telos of right and good care of the pain patient. The intricate nature of the relationship between pain, the pain patient, and the pain physician, can create pragmatic and moral dilemmas that may not be well served by sole use of prima $f a$ cie principles. Rather, I argue that agentbased, virtue ethics provides the substantive moral grounding that best enables the clinician to both apprehend the intellective complexity of pain, the pain patient, and pain therapeutics, and to sensitively appreciate the viability of other ethical voices in discourse arising from the issues inherent to medical care.

\section{The Philosophy of Medicine}

A philosophy applicable to medicine was derived from studies of metaphysical, epistemological, and ethical inquiry within natural philosophy during the late 17 th and early 18th centuries (1). The formalized philosophical concern with issues, questions, and dilemmas of medical study apprehend the complexity of this relationship and appreciate other ethical approaches in the discourse arising from issues of care.

Key words: Pain medicine, philosophy, patient-physician relationship, virtue, ethics

and practice arose in earnest from what has become known as the Polish School during the latter 19th and early to mid20th centuries. Representative of this atheneum, the work of Chalubinski, Bieganski, Kramsztyk, and Fleck, while incipient, was nonetheless extensive in scope, and pioneered the expansion of the field as a discipline $(2,3)$.

More recently, there has been debate as to whether a philosophy of medicine 1) does exist, and 2) should exist. With regard to the former, the discussion has centered upon whether philosophical issues focal to medicine actually constitute an independent domain of study, or are more appropriately regarded as intellectual enterprises of other disciplines (e.g., the humanities) applied to medicine (4). There is much to refute in this position. Clearly, there are examples of humanities in medicine (e.g., medical literature) and extant relationships of humanities' disciplines to medicine (e.g., medical sociology). However, a philosophy of medicine seeks distinct study of, and involvement with, those aspects of the field that are essentially unique (5). As well, it has been shown that the philosophy of medicine has qualities of both a defined field of inquiry and a discipline, and although somewhat nascent, has a progressively developing canon $(6,7)$.

The second criticism is based upon the assumption that if such a philosophy exists, it is too reductive in scope, and as such, is trivial and/or superfluous (8). I oppugn this argument for two reasons: 
first, because of the aforementioned historicity of the field; and secondly, because of the fact that medicine is characteristically different from other professions in its focus upon the knowledge, problems, phenomena, and obligations that comprise the interpersonal relationship between a person who is ill, and one who declares to possess the capacities of a healer (9). Of course, there are epistemic foci that may be addressed by and through the philosophy of science, and historical, linguistic, social, and theosophic issues that may be addressed through the humanities. Yet, while each of these may allow inquiry to a particular domain that constitutes a component of medicine (e.g., science, logic, psychology, etc.), they are insufficient to accurately encompass the breadth of applications that are relevant to medicine as an entirety (vide infra).

Thus, contemporary philosophy of medicine is concerned with the ends, processes, and acts that are integral to the domains that medicine occupies as a science, social and cultural entity, and as a humanitarian endeavor. The physician-philosopher Henk ten Have has elucidated three "traditions" that characterize the contemporary approach (10). First is the epistemological tradition that seeks to determine the nature, type, and meaning(s) of knowledge that are requisite to medicine as both science and practice. Second, the anthropologic tradition emphasizes the human dimension(s) of medicine, and the subjective nature of the physician and patient as being vital to the context of medicine as an interpersonal act. Third is the ethical tradition, which must account for both epistemic and anthropologic models, and which has seen the most significant growth and embellishment over the past 20 years.

This ethical tradition has generated much of the recent work that has addressed what a philosophy of medicine actually is, and what and how the conduct of medicine should be. The most prominent advocate for such a definable philosophy of medicine is Edmund Pellegrino (11-13). Pellegrino's conceptualization of a philosophy of medicine is derived from an identification of the elements of medicine that are critical to its establishment as a unique field; these are: 1) the fact of illness; 2) the act of profession; and, 3) the act of medicine (11). Each of these contribute to the special relationship of the physician to the patient, and in so doing establish and concretize the telos of medicine in that: 1) the nature of vulnerability incurred by illness is multidimensional (i.e., it is both physical and ontological); and 2) the physician's act of profession serves as a promise that the technical skills and knowledge offered are authentic and are dedicated to the obligations inherent to the act of medicine (12).

In this regard, the physician must utilize these abilities to determine 1) what is the nature of the illness, 2) what can be done to address the condition, and 3) what should be done for a particular patient. Clearly, by reducing medicine to its essence, Pellegrino's philosophy of medicine competently serves the epistemic and anthropologic traditions identified by ten Have (10). This "essentialist" philosophy of medicine is foundational to the ethical "tradition" that arises from it to meet the moral obligations concordant with the telos of a technically right and morally good healing (13).

But what constitutes what is right and good? The intricacies of the patient-physician relationship are such that no single set of rules could be uniformly applicable in the process of decision-making and care. Thus, for Pellegrino (11-13), the emphasis is not upon rules or acts, but upon the physician's character as it is disposed to means and actions that best adhere to the telos of medicine. It is in this light that he supports a return to virtue ethics as a normative grounding of moral agency in medicine (14). (For alternative perspectives upon the philosophy of medicine, see Engelhardt (15) and Tauber (16).)

I agree with Pellegrino and similarly assert that virtue must be situated within a larger philosophical framework and defined as relevant to the practice at hand. I feel this is especially true for pain medicine. Using a phenomenologic orientation to medicine and pain, I have previously attempted to elucidate how their intersection establishes a philosophical, pragmatic, and ethical uniquity, based upon the subjective and enigmatic nature of pain, and the troubling, persistent diagnostic and therapeutic challenges that these incur (17). I have argued that pain medicine requires both a core philosophy and a virtue-based foundation to most effectively confront these challenges, a position that is reaffirmed here through discussion of the practice and key virtues important to pain medicine.

\section{The Act of Profession, and the Practice of Pain Medicine \\ "Know thy self; Know thy limits." The Pillars at Delphi}

The clinician who professes to be a pain specialist is vocationally committed to the defined ends of rendering technically right and ethically good care to those made vulnerable by pain. This act of profession is a literal declaration that the clinician possesses the knowledge, skills and abilities to understand the problem of pain, as well as its implications and manifestations upon the person who is the patient. In this way, the professional bespeaks their stewardship of knowledge, not just of the origins of pain and its treatment, but also of the empirical and contextual domains that reflect a broad understanding of the condition of a specific person in pain. This knowledge enables accurate diagnosis, and empowers prudential decisions of what should be done to best treat this patient. Thus, the act of profession explicitly invites the patient to trust that the clinician will act toward the primacy of the patients' best interest(s). In responsibly upholding this relationship of trust, the clinician acts as both a therapeutic and a moral agent.

Multiple disciplines exist under the general category of pain medicine, and the therapeutic agency of each discipline contributes particular clinical perspectives and parameters that establish the specific technicalities of care. What can be done for a particular patient is often contingent upon the scope and/or limitations of a given practitioner's discipline. Certainly, many of the disciplines in pain medicine have over-arching practice parameters (e.g., diagnosis, pharmacological management, etc.), while others are more distinct (e.g., surgery, behavioral medicine, etc.); each may approach the clinical encounter with somewhat unique knowledge and skill sets. However, if not focused upon and adherent to the technically right and ethically good care of the pain patient, this heterogeneity of orientations, therapeutics, and perhaps practice ideologies may contribute to a lack of cohesive (or proper) care that is provided through an inexact rubric of "pain medicine." Recall that the prudential question is what should be done to best treat a particular patient. Thus, the defining variables that determine the type and course 
of treatment are not the discipline-specific tools and techniques that are available to a clinician, but the nature and effects of a patient's pain. It is from this point that the pain clinician can decide whether their skills and scope of practice are capable of best meeting the medical needs of a given patient and/or if other domains of care are required, thereby necessitating a more collaborative, interdisciplinary approach. To be sure, there are times when a uni-disciplinary approach may suffice to serve either a curative or healing model. Yet, given the inherent complexity of longitudinal, more intractable pain, curative approaches may not be viable, and healing and caring needs are better met through the participation of multiple disciplines that each seek attainment of defined clinical goals that are focal to the telos of pain medicine. Where and how a particular discipline fits into the "grand scheme" of pain therapeutics is based upon how the abilities conferred by that practice can best serve the common ends of pain medicine as a whole. Determining what discipline (i.e., "who") will "steer" the therapeutic trajectory depends upon the nosologic character of the pain pathology and its expression in, and influence upon, the lived body and life world of the patient. Working within this paradigm, the relative hegemony of a particular discipline in the medical care of a specific pain patient is dictated by the therapeutic requirements imposed by pain, and thus are unique to each patient and may change over time.

\section{Pain and the Patient-Centered Telos of Pain Medicine}

Pain may be the result of an identifiable noxious stimulus (i.e., nociceptive pain) or may occur through neuropathic mechanisms that involve peripheral and/ or central sensitization and perhaps neural remodeling $(18,19,20)$. Thus, pain may be conceptualized as a spectral disorder that can range from being a symptom of an injury or disease process to manifesting a phenomenal illness capable of affecting multiple physiological systems and more global domains of the existential condition of the person in pain (21). The activation of distinct neural substrates involved in pain processing can elicit cognitive, emotional and behavioral events to produce very different subjective and affective experiences of pain (22). In this light, it can be seen that the complexity of pain imparts considerable heterogeneity to the population of pain patients; genotypic, phenotypic, environmental, and cultural variables can all be affected, and reciprocally can affect a patient's pain, and consequently the dimensions of care that are required. To apprehend the nature and extent of each patient's pain, the clinician must utilize both objective data as well as subjective narrative to establish a categorical diagnosis that provides rationalization for subsequent care. This relationship between patient and physician establishes a covenant that reflects the clinician's commitment to the telos of effective and beneficent treatment (23). The complexity of pain and the changing exigencies of the pain patient can foster a variety of technical, economic, and personal circumstances that can generate ethical dilemmas within this clinical relationship that may influence the course and integrity of care. Although commonly known and widely utilized in healthcare, the sole utilization of prima facie principles may be inadequate to effectively resolve ethical dilemmas inherent to pain medicine. The highly pluralistic society in which we live, and the oftentimes capricious nature of medical economics could create serious and significant distortion in the vocabulary of ordered principles, undermining and even eliminating their meaning, and creating circumstances in which these principles are placed in direct conflict with themselves.

\section{Moral Agency and Virtue Ethics in Pain Medicine}

Certainly rules and principles are important, but the profound nature of pain, the need for both equanimity and empathy toward suffering, and the inter-subjective nature of right and good pain care all heavily rely upon the moral agency of the clinician. In light of this, I have argued for the necessity of an agent-based virtue ethics of pain medicine (17). Such virtue ethics do not negate the use of principles. To the contrary, intellectual and moral virtues enable the physician to understand and utilize principles, together with other ethical approaches (care-based ethics, feminist approaches, casuistry, etc.) in the resolution of specific dilemmas in ways that are consonant with the telos of pain medicine. The virtues cannot, and should not, stand alone as an egoistic approach to pragmatic and moral dilemmas. Virtue ethics are genuinely compatible with oth- er ethical approaches (24-26). The diversity of circumstances from which ethical dilemmas arise, and the richness of the contemporary ethical milieu, necessitate finding and relying upon such compatibility.

Herein is presented the Aristotelian definition of virtue(s) as those conditions of character that habitually dispose excellence in intentions and actions toward a definable good that is specific to the telos of a particular activity or practice (27). I believe that the virtues that define the character of the good pain physician are those that are vital to attaining the ends consistent with the philosophy and profession of medicine, and are based upon the primacy of doing good (i.e., benevolence) in the intentions and acts of patient care. The following list is in no way encompassing, however, it presents those aforementioned virtues that are fundamental to the practice of pain medicine. (For a complete review of virtue(s), and thorough discussion of virtue ethics, see Aristotle (27) and MacIntyre (28), respectively).

\section{Benevolence}

I maintain that benevolence establishes a moral cornerstone upon which all other intellectual and ethical acts of medical agency are predicated. It is from the benevolent intention and beneficent acts of the physician that the (somewhat more passive) maxim of non-harm (i.e., non-maleficence) is derived and realized (29). Benevolence also entails a fidelity to the covenant of caring for the patient. This beneficence-in-trust obligates the clinician to uphold therapeutic and moral responsibility to the patient and ensures against abandonment $(30,31)$. The responsibility borne of this beneficence seeks a four-fold good: 1) provide the patient with care that is biomedically correct and appropriate; 2) to provide care that acknowledges the patient's choices; 3 ) to provide care for the good of the patient as a person, thus enabling the clinical encounter qua humanitarian act; and 4) to provide good that has existential meaning for the patient (31).

\section{Compassion and caring}

By acting at the four-fold good mentioned above, benevolence becomes synergistic with the virtues of compassion and caring. Compassion originates from an objective assessment of the patient's predicament of pain, balanced with a sub- 
jectivity through which the clinician can better apprehend the phenomenal experience and effects of pain upon the patient's lived body and life world $(32,33)$. Such equilibrium, in an Aristotelian sense, reconciles, at least in part, the dialectic surrounding the respective roles and relative importance of empathy and equanimity in the domains of understanding inherent to medicine. Through this understanding, the concerns and needs of the patient can be addressed, thus providing a basis for care. Through this sensitivity to the inequities of empowerment, the concern for vulnerability, subjective identity, and the imperative to regard the needs of the patient, it can be seen that this type of virtue ethics is generally supportive of care-based, and some feminist, ethical approaches as recently advocated (34).

\section{Justice}

The benevolent medical relationship involves acts and provision of services by the clinician to those patients who express and demonstrate the need for healing and care. Thus, in this context, the virtue of justice is based upon the direct, interpersonal relationship of physician and patient $(14,35)$. However, the act of profession and covenant of care also establish a potential for other persons to enter and be conjoined to the faith and trust characteristics of the medical relationship. Thus, while there is a certain partialism that reasonably justifies the extent of care to those patients being treated at the present time, the nature of this care should be extendable to others who enter the medical relationship in the future (36). In this way, the act of medicine fulfills both a direct obligation to provide good care to a particular patient, and serves the broader good of humanitarian caring. Yet, it is important to recognize that economic, social, and political issues realistically affect the distributive aspects of just provision of healthcare. Such complex forces are often inimical to the ethically sound practice of pain medicine. Although a complete discussion of moral issues arising from the increasing commodification of medicine are beyond the scope of this paper, suffice it to say that the radically divergent ends of corporate and clinical medicine have led to considerable ethical tensions that surround the quality and quantity of care.

It can be seen that a significant onus of moral responsibility is placed upon the clinician to act in advocacy for the good of the patient. But the obligation to determine the technically correct and ethically appropriate care of each and every patient does not require the physician to explicitly act as a gate keeper. To reiterate, it is the patient's needs that should dictate the extent, duration and ultimate trajectory of treatment. Each pain patient brings unique pre- and co-morbidity and predispositions (e.g., psychiatric conditions, addictions, etc.) to the medical relationship, that the clinician must recognize, frame within the bio-psychosocial contexts relevant to pain, and act to treat and/or refer for appropriate care. The presence of such co-morbidity and pre-dispositions does not negate the patient's pain, or the need for effective pain therapeutics. Frequently, such patients can, and should be co-managed in the best manner to achieve positive therapeutic outcomes.

\section{Veracity and Intellectual Honesty}

The medical relationship is characterized by inequity of power; this exists as a consequence of the patient's vulnerability incurred by pain and illness, and by the disproportionate knowledge that is maintained by the clinician. As the steward of such knowledge, the clinician has an obligation of truthfulness to the patient, and is equally obligated to intellectual honesty that acknowledges their own limitations of understanding and ability. Such veracity empowers the patient to act as an informed agent within the medical relationship to engage participation in self-referent decisional processes. This empowerment upholds respect for the dignity of the person and thereby diminishes the vulnerability inherent to being a patient. (For a specific discussion of the obligation(s) of veracity and intellectual honesty relevant to the diagnosis and treatment of intractable pain, see Giordano (37)).

The existential dilemma of the patient in pain can be considerable, and the current commodified environment of medicine can easily create circumstances in which a business ethic applied to medicine could subordinate the moral primacy of the patients' good. Thus, a certain degree of effacement of self-interest is necessary in light of the power of the physician to exploit the intellectual, physical, emotional, and economic vulnerability of the patient (38).

\section{Practical Wisdom (phronesis)}

The intellectual virtue of practical wisdom, defined by Aristotle as phronesis, and by Aquinas as prudence, enables the clinician to utilize distinct domains of knowledge to evaluate information and resolve ethical issues in the rational execution of optimal care of specific patients. Elsewhere when discussing this issue, I have relied upon Davis' thesis of the indispensibility of phronesis in medical practice to illustrate its role in the decisional processes inherent to pain medicine $(17,39,40)$. Contrary to Waring (41), I hold that phronesis serves as a critical fulcrum upon which intellectual and moral virtues, as well as other ethical approaches, can be balanced in the formulation of diagnoses and implementation of therapeutics. In this way, the relationship of phronesis to the ethical utilization of both general and categorical knowledge relevant to the clinical encounter with a specific patient becomes manifest. As such, phronesis affords the ability to act virtuously in circumstances of ethical discord and pragmatic uncertainty (42).

\section{Fortitude}

Frequently, acting virtuously and consistently with a patient-centered telos will necessitate significant personal and professional fortitude. Justice and effacement of self interest against a tide of commodification, along with intellectual honesty and veracity against opportunism and dogmatism, may require considerable integrity and courage to maintain in the somewhat morally skeptical predominating culture of marketplace medicine. Deciding to enter the field of pain medicine, and thus to call oneself a pain physician, is voluntary; the ethical obligations inherent to that act of profession are not. While it is virtuous to uphold the best interests of the patient through intention and action, it is equally important that the clinician act within the scope of law and social justice to execute the goods inherent to the practice of pain medicine. Maintaining this balance can be arduous; the responsibilities cannot be assumed cavalierly, and conscious moral commitment to this practice is essential.

\section{Arguments Against Virtue Ethics in Medicine}

In general, the argument against virtue ethics is based upon the assumption that such a moral grounding, while normative, lacks application and thus does not specifically address acts or action 
(43). Certainly, any system of virtue ethics is normative, but this distinction from applied ethics is somewhat arbitrary, at very best. In actuality, normative and applied ethics are situated along a continuum based upon how particular moral claims are framed and directed within given contexts (44). In this way, the moral claims of virtue ethics can indeed be both normative and applied. Similarly, the criticism that any system of virtue ethics would provide insufficient guidance for acts and action fails to acknowledge the elements of any definable human encounter, namely agents, circumstances, acts, and consequences (45). Thus, while virtue ethics is concerned with the dispositional nature of character (i.e., what one should be), the agency of individuals in any circumstance ultimately involves acts that are directly predicated upon these ingrained traits.

A second criticism is that the diversity of modern human societies and values make "virtue" an imprecise, and conceptually anachronistic construct, and thus any attempt at a virtue-based system of morality is impractical, if not implausible (46). From this is derived the argument that social values define the meaning and practice of medicine as a contract between specific citizens of a society and its physicians (47). I oppose these arguments as false on the following grounds. First, while globalization indeed has led to a considerably more accessible world community, this does not negate mutually acceptable moral values and conduct. Such a "common morality" has been proposed by Gert, Culver and Clouser (48) who have identified cardinal and derivative values

Author Affiliation:

James Giordano, PhD

Scholar-in-Residence

Center for Clinical Bioethics

Georgetown University Medical Center 4000 Reservoir Rd.

Washington, DC 20057

and, Visiting Fellow

John McGovern MD Center for Health,

Humanities and the Human Spirit

University of Texas Health Sciences

Center

Houston, TX

E-mail: jgiordano@neurobioethics.org that are essentially based upon personal integrity and a universal imperative not to harm, and thus are consistent, to a considerable extent, with a system of agent-based virtue ethics (48). Second, despite ongoing debate about the social construction of medicine, I maintain that such constructivism denies that the moral basis of medicine is derived from the structure and function integral to the patient/physician relationship. Attempts at pure social definitions and direction of medicine threaten the perdurability of trust that has been traditionally represented by this relationship. One need only to look at Nazi medicine as an extreme example of the possible course that such absolute social constructivism may take. Third, while there has been considerable impetus to create a consumer orientation within a commodified medical market, this business ethos essentially disavows the nature of medicine and threatens the very foundation of the moral obligation of physician to patient. While medicine may serve a social good (49), its ends (i.e., healing and health) are fundamental, not instrumental, thus the requisite acts, practices, and services toward these ends should not be commodified. Patient consumerism corrupts the probity of autonomy and can result in economic and legal burdens that may dictate and denigrate the nature and quality of care. Lastly, the obligation of the physician

\section{REFERENCES}

1. King LS. The Philosophy of Medicine: The Early Eighteenth Century. Harvard University Press, Cambridge, 1978.

2. Löwy I. The Polish School of Philosophy of Medicine: From Tytus Chalubinski (18201889) to Ludwik Fleck (1896-1961). Kluwer, Dordrecht, 1990.

3. Stempsey WE. The philosophy of medicine: Development of a discipline. Medicine, Health Care and Philosophy 2004; 7: 243-251.

4. Caplan AL. Does the philosophy of medicine exist? Theor Med 1992; 13:67-77.

5. Wulff HR. Philosophy of medicine - From a medical perspective. Theor Med 1992; 13: $79-85$.

6. Velanovich V. Does the philosophy of medicine exist? A commentary on Caplan. Theor Med 1994; 15:77-81.

7. Engelhardt HT, Schaffner KF. Medicine, philosophy of. In Routledge Encyclopedia of Philosophy. Routledge, New York, 1998, pp 17-45. to the patient is not contractual, but is an implied covenant that assures both proximate and continued care based upon the patient's plight of illness and the physician's act of profession (50). Unlike a contract that assumes a relative equity and optional participation of the involved parties, the patient/physician relationship is one of intrinsic inequity and the patient's existential condition of illness is not discretionary.

\section{Conclusion}

The physician who enters the field of pain medicine does so by choice. In professing to be a "pain physician," one assumes the responsibility of acquiring and maintaining knowledge and skill that are both general to an overall understanding of pain, its diagnoses, and treatment requirements, and are specific to the scope and parameters of their particular practice. While these responsibilities may enable therapeutic agency, the physician is equally responsible as a moral agent. The intentions and acts of the practice of pain medicine reflect the character of such agency. Virtue, as framed within a philosophy that defines the ends of technically right and ethically good care of the pain patient, thus establishes a grounding when used with other ethical constructs, and may empower the pain physician to best meet the moral and intellectual challenges of their chosen profession.

8. van Leeuwen E, Kisma GK. Philosophy of medical practice: A discursive approach. In Thomasma DC (ed.), The Influence of Edmund D. Pellegrino's Philosophy of Medicine. Kluwer, Dordrecht, 1997, pp 99112.

9. Pellegrino ED. Philosophy of medicine: Problematic and potential. I Med Philosophy 1976; 1:5-31.

10. ten Have H. Bodies of knowledge, philosophical anthropology and philosophy of medicine. In Engelhardt HT (ed.), The Philosophy of Medicine: Framing the Field. Kluwer, Dordrecht, 2000, pp 19-36.

11. Pellegrino ED, Thomasma DC. A Philosophical Basis of Medical Practice: Toward a Philosophy and Ethic of the Healing Professions. Oxford University Press, New York, 1981.

12. Pellegrino ED. Toward a reconstruction of medical morality: The primacy of the act of profession and the fact of illness. J Med Philosophy 1979; 4:32-56.

13. Pellegrino ED. What the philosophy of 
medicine is. Theor Med Bioethics 1998; 19:315-336.

14. Pellegrino ED. Toward a virtue-based normative ethics for the health professions. Kennedy Institute of Ethics Journal 1995; 5:253-277.

15. Engelhardt HT. From philosophy and medicine to philosophy of medicine. J Med Philosophy 1986; 11:3-8.

16. Tauber Al. From the self to the other: Building a philosophy of medicine. In Grodin MA (ed.), Meta-Medical Ethics: The Philosophical Foundations of Bioethics. Kluwer, Dordrecht, 1995, pp 158-195.

17. Giordano J. Toward a core philosophy and virtue-based ethics of pain medicine. Pain Practitioner 2005; 15:59-66.

18. Knotkova H, Pappagallo M. Peripheral mechanisms. In Pappagallo M (ed.), The Neurological Basis of Pain. McGraw-Hill, New York, 2005, pp 53-60.

19. Woolf CJ, Mannion RJ. Neuropathic pain: Aetiology, symptoms, mechanisms and management. Lancet 1999; 353:1959.

20. Giordano J. The neurobiology of nociceptive and anti-nociceptive systems. Pain Physician 2005; 8:277-291.

21. Leder D. Toward a phenomenology of pain. Review of Existential Psychology and Psychiatry 1984; 9:29-43.

22. Hudson AJ. Pain perception and response: Central nervous system mechanisms. Can J Neurol Sci 2000; 27:2-16.

23. Pellegrino ED. The healing relationship: The architectonics of clinical medicine. In Shelp E (ed.), The Clinical Encounter: The Moral Fabric of the Patient-Physician Relationship. Philosophy and Medicine Series, volume 4. D. Reidel, Dordrecht, 1983, pp 153-172.

24. Watson G. On the primacy of character. In Darwall S (ed.), Virtue Ethics. Blackwell Publishing, Malden, MA, 2003, pp 229-250.

25. Slote M. From Morality to Virtue. Oxford University Press, New York, 1992.
26. Frankena W. A critique of virtue-based ethics. In Pojma L (ed.), Moral Philosophy, $A$ Reader, 2nd edition. Hackett Publishing, Indianapolis, 1998, pp 264-270.

27. Aristotle. Nicomachean Ethics, Books II and III. Irwin T (trans.) Hackett Publishing, Indianapolis, 1999.

28. Macintyre A. After Virtue: A Study in Moral Theory, 2nd edition. University of Notre Dame Press, Notre Dame, IN, 1984.

29. Pellegrino, ED. The telos of medicine and the good of the patient. In Viafora C (ed.), Clinical Bioethics: A Search for the Foundations. Springer, Amsterdam, 2005, pp 21-32.

30. Quill TE, Cassel CK. Non-abandonment: A central obligation for physicians. Ann Intern Med 1995; 121:368-374.

31. Pellegrino, ED, Thomasma DC. For the Patient's Good: The Restoration of Beneficence in Health Care. Oxford University Press, New York, 1987.

32. Glick SM. The empathic physician. In Spiro $\mathrm{H}$, McCrea-Curnen MG, Peschel E, St. James D (eds.), Empathy and the Practice of Medicine. Yale University Press, New Haven, 1993, pp 85-102.

33. Osler W. Aequanimitas with Other Addresses to Medical Students, Nurses and Practitioners. Keynes Press, London, 1904.

34. Baier A. What do women want in a moral theory? Nous 1985; 19:53-65.

35. Maclntyre A. Whose Justice? Which Ratio nality? University of Notre Dame Press, Notre Dame, IN, 1988.

36. Slote M. Virtue ethics. In LaFollette H (ed.) The Blackwell Guide to Ethical Theory. Blackwell Publishing, Malden, MA, 2000, pp 325-347.

37. Giordano J. Bioethics and intractable pain. Practical Pain Management, 2005; 5:72-79.

38. Pellegrino ED. Professionalism, profession and the virtues of the good physician. Mt. Sinai J Med 2002; 69:378-384.
39. Davis FD. Phronesis, clinical reasoning and Pellegrino's philosophy of medicine. Theor Med 1997; 18:173-195.

40. Tyreman S. Promoting critical thinking in health care: Phronesis and criticality. Medicine, Health Care and Philosophy 2000; 3:117-124.

41. Waring D. Why the practice of medicine is not a phronetic activity. Theor Med Bioethics 2000; 21:139-151.

42. Thomasma DC. Aristotle, phronesis and postmodern bioethics. In Kuczewski $M$, Polansky R (eds.), Bioethics: Ancient Themes in Contemporary Issues. MIT Press, Cambridge, MA, 2000, pp 67-91.

43. Gauthier D. Morals by Agreement. Oxford University Press, Oxford, UK, 1986.

44. Kagan S. Normative Ethics, Westview Press, Boulder, 1998.

45. Aristotle. Metaphysics. In McKeon R (ed.), The Basic Works of Aristotle. Random House, New York, 1941.

46. Veatch RM. The impossibility of a morality internal to medicine. J Med Philosophy 2001; 26:621-642.

47. Veatch RM. Revisiting a theory of medical ethics: Main themes and anticipated changes. In Walter JK, Klein EP (eds.), The Story of Bioethics: From Seminal Works to Contemporary Explorations. Georgetown University Press, Washington DC, 2003, pp 67-90.

48. Gert B, Culver CM, Clouser KD. Bioethics: $A$ Return to Fundamentals. Oxford University Press, New York, 1997.

49. May WF. Contending images of the healer in an era of turnstile medicine. In Walter JK, Klein EP (eds.), The Story of Bioethics: From Seminal Works to Contemporary Explorations. Georgetown University Press, Washington DC, 2003, pp 149-162.

50. May WF. The Physician's Covenant, revised edition. Westminster Press, Philadelphia, 2000. 